\section{The positive association between serum uric acid, impaired fasting glucose, impaired glucose tolerance, and diabetes mellitus in the ELSA-Brasil study}

\author{
Associação positiva entre ácido úrico sérico, \\ glicemia em jejum alterada, tolerância glicêmica \\ alterada e diabetes mellitus no estudo \\ ELSA-Brasil \\ La asociación positiva entre ácido úrico sérico, \\ glucosa alterada en ayunas, tolerancia a la \\ glucosa alterada y diabetes mellitus en el \\ estudio ELSA-Brasil
}

Aline Isabel Rodrigues Galvão 1

Alline Maria R. Beleigoli 2

Pedro Guatimosim Vidigal 3

Bruce Bartholow Duncan 4

Maria Inês Schmidt 4

Sarah L. Appleton 5

Sandhi Maria Barreto 3

Maria de Fátima Haueisen Sander Diniz 3

doi: 10.1590/0102-311X00255920

\begin{abstract}
There is a conflict in the literature regarding the association between serum uric acid (SUA) levels and glycemic status. Therefore, we evaluated the association between SUA level and glycemic status - impaired fasting glucose (IFG), impaired glucose tolerance (IGT), and diabetes mellitus - and insulin resistance, in a large Brazilian study. This is a cross-sectional, observational study with 13,207 participants aged 35-74 years, at baseline (2008-2010) of the Brazilian Longitudinal Study of Adult Health (ELSA-Brasil). A multinomial regression analysis was performed to test the association between SUA and glycemic status (IFG, IGT, and newly diagnosed type 2 diabetes at the cohort baseline) after adjustments by age, sex, skin color, body mass index, physical activity, smoking, alcohol consumption, comorbidities, and medicines use. Logistic regression model was used to evaluate the association between SUA and insulin resistance by HOMA-IR. Stratified analyses by sex were performed. The mean age (standard deviation) was 51.4 (8.9) years, 55.2\% of participants were women. There were 1,439 newly diagnosed diabetes. After all adjustments, higher SUA was associated with IFG, IGT, and diabetes, with odds ratio $(\mathrm{OR})=1.15$ (95\%CI: 1.06; 1.25), 1.23 (95\%CI: 1.14; 1.33), and 1.37 (95\%CI: 1.24; 1.51), respectively. There was association between SUA levels and insulin resistance with $O R=1.24$ (95\%CI: 1.13; 1.36). In analysis stratified by sex, higher SUA persisted independently associated with impaired glycemic status. Our results suggest that a higher SUA levels were significantly associated with glycemic status in a large Latin American population, mainly among women.
\end{abstract}

Diabetes Mellitus; Uric Acid; Impaired Glucose Tolerance; Insulin Resistance

\section{Correspondence}

M. F. H. S. Diniz

Faculdade de Medicina, Universidade Federal de Minas Gerais. Av. Alfredo Balena 190, 2o andar, sala 246, Belo Horizonte, $M G$ 30130-100, Brasil.

mfhsdiniz@yahoo.com.br

1 Hospital das Clínicas, Universidade Federal de Minas Gerais, Belo Horizonte, Brasil.

2 Flinders University, Adelaide, Australia.

3 Faculdade de Medicina, Universidade Federal de Minas Gerais, Belo Horizonte, Brasil.

${ }_{4}$ Faculdade de Medicina, Universidade Federal do Rio Grande do Sul, Porto Alegre, Brasil.

5 University of Adelaide, Adelaide, Australia. 


\section{Introduction}

Diabetes mellitus is a public health problem. Being a highly prevalent condition that increases cardiovascular risk and associated morbimortality, diabetes is associated with high health expenditures and large economic impact on health systems ${ }^{1}$. About 463 million adults were diagnosed with diabetes worldwide by 20192 2. If effective interventions are not performed, diabetes will be present in over 700 million adults, by 20251.

Several risk factors that contribute to the development of diabetes are well known, such as obesity and sedentary lifestyle 1 . Uric acid is the final product of purine metabolism under the action of the xanthine oxidase enzyme 3 . Higher serum uric acid (SUA) levels are associated with the development of gout, cardiovascular diseases, renal disease, and inflammatory process 3 . The association between elevated SUA levels and increased risk of hyperglycemia has been reported by some authors 4,5,6,7,8. A meta-analysis showed that elevation of $1 \mathrm{mg} / \mathrm{dL}$ in the SUA level was associated with a $17 \%$ risk increase of developing diabetes. Moreover, it was suggested that the increase of $1 \mathrm{mg} / \mathrm{dL}$ on uricemia would be comparable to the increase of $1 \mathrm{~kg} / \mathrm{m}^{2}$ in body mass index (BMI) for the development of type 2 diabetes 4 . In contrast, other studies, including some with genetic evaluation, have not shown positive association between higher uricemia and hyperglycemia 9,10,11. Studies have found that urate is involved in oxidative stress, systemic inflammation, insulin sensibility, and intrahepatic fructose metabolism 12 .

SUA test is an accessible and simple laboratorial test, and is a potentially modifiable factor. Investigating whether SUA levels are associated with diabetes, pre-diabetes status, and insulin resistance may be relevant for clinical and public health purposes. To date, these studies are lacking in a large mixed-race and multi-ethnic populations. Brazil is a developing country, with more than 210 million inhabitants distributed in the territory of continental dimensions, and with some epidemiological profile distinct from other countries. We did not find Latin America studies evaluating the association between uricemia and diabetes, and epidemiological studies about uricemia are scarce and small. Meta-analysis evaluated do not include studies with specifically Latin American populations.

Thus, we aim to investigate a possible association between SUA levels and impaired glycemic status; and between SUA and insulin resistance, at the baseline of a large Brazilian prospective study, the Brazilian Longitudinal Study of Adult Health (ELSA-Brasil).

\section{Methods}

This is a cross-sectional study using ELSA-Brasil baseline data, collected from August 2008 to December 2010. The study population consisted of 15,105 participants aged 35-74 years. This multicenter Brazilian cohort study involves five public universities and one research institution, from three of the five major regions of the country. It aims to investigate epidemiological, clinical, and molecular aspects of chronic non-communicable diseases - mainly cardiovascular disease and diabetes 13,14.

Data collection started in 2008, according to study manuals and following international regulation for storage and data analysis. Interviews were performed after all participants signed the free consent form. Additional interviews, examinations, and laboratory tests were performed subsequently 13,14 . The ELSA-Brasil study was supported by the Brazilian Ministry of Health and the Brazilian Ministry of Science and Technology. More information is available at http://www.elsa.org.br/.

Our hypothesis is that there is a positive association between SUA levels and diabetes, impaired fasting glucose (IFG), and impaired glucose tolerance (IGT). For this analysis, the exclusion criteria were: participants with previous self-reported medical diagnosis of diabetes or in use of oral antidiabetic medications or insulin ( $n=1,407)$; with reported bariatric surgery $(n=120)$ or allopurinol use ( $n=153$ ); without previous diabetes information status $(n=4)$; with missing values for fasting glucose $(\mathrm{FG})(\mathrm{n}=3)$, glycated hemoglobin A1c $(\mathrm{n}=14)$, oral glucose tolerance test (OGTT) $(\mathrm{n}=192)$ and uric acid $(\mathrm{n}=5)$. The final sample was composed of 13,207 participants $(87.4 \%)$ (Figure 1$)$. 
Figure 1

Study population selection. ELSA-Brasil baseline (2008-2010).

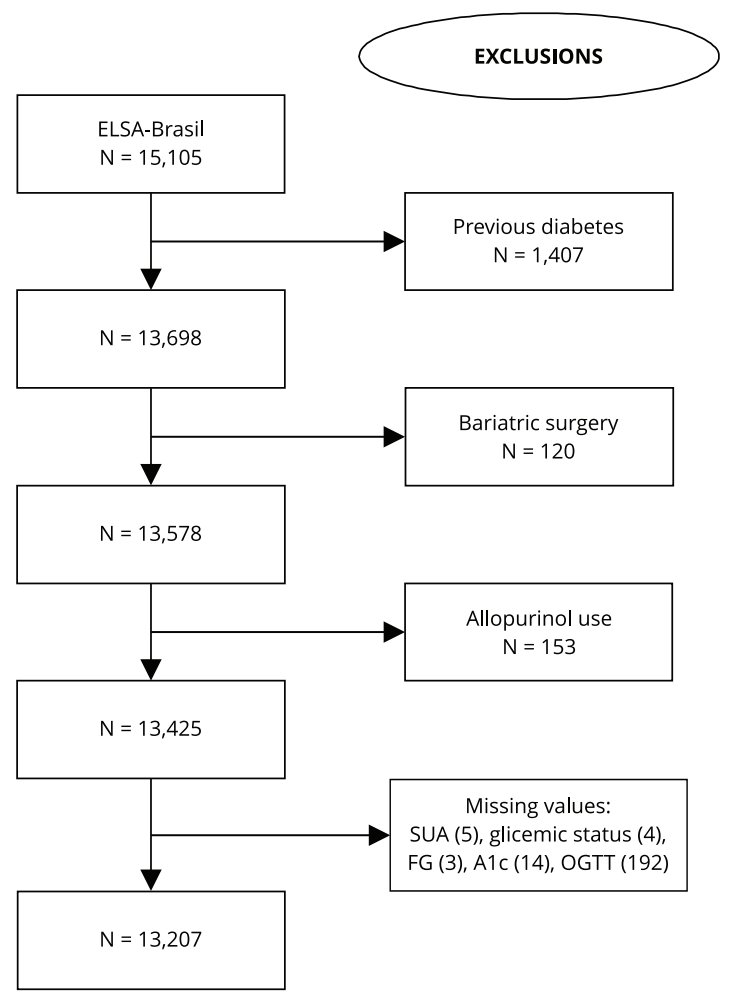

A1c: glycated hemoglobin A1 c; FG: fasting glucose; OGTT: oral glucose tolerance test; SUA: serum uric acid.

\section{Laboratory tests}

After overnight fasting, biological material samples were collected from all participants and were initially frozen and stored, and then transported to the central laboratory (University of São Paulo). All laboratory analysis were carried out in a single research center for better standardization 15 .

The standard OGTT was performed in all participants of this study. Samples were collected for FG, after two hours of oral overload with $75 \mathrm{~g}$ of anhydrous glucose 15 .

Uric acid was measured by uricase method (enzymatic colorimetric) in the Siemens 1200 (Siemens Healthcare Diagnostics, Deerfield, Unites States). Hyperuricemia was defined on the basis of genderspecific cut-off points ( $>7.2 \mathrm{mg} / \mathrm{dL}$ for men, and $>6.0 \mathrm{mg} / \mathrm{dL}$ for women) 15 .

FG was measured by an enzymatic hexokinase (enzymatic colorimetric) method in Siemens 1200, glycated hemoglobin (A1c) by a high performance liquid chromatography (HPLC) in BioRad Laboratories (Hercules, United States), and insulin by an immunoenzymatic assay, in Centaur Siemens equipment.

Triglycerides: Glycerol-phosphate peroxidase according to trinder (enzymatic colorimetric) and HDL cholesterol, in ADVIA 1200 Siemens equipment.

Creatinine measurement was based on the Jaffe's method in ADVIA 1200 Siemens equipment. The glomerular filtration rate (GFR) was estimated by serum creatinine, age, and sex, using the abbreviated form of Chronic Kidney Disease Epidemiology Collaboration (CKD-EPI) 16. 


\section{Measures and definitions}

"Glycemic status" was categorized into four categories: normoglycemia (normal FG and OGTT, and A1c < 5.7\%), IFG (100mg/d/L $\geq$ FG < 126mg/dL and OGTT < 140mg/dL and A1c < 5.7\%), IGT $(140 \mathrm{mg} / \mathrm{dL} \geq \mathrm{OGTT}<200 \mathrm{mg} / \mathrm{dL}$ and/or HbA $1 \mathrm{c}>5.7 \%$ and $<6.5 \%)$, and diabetes (FG $\geq 126 \mathrm{mg} / \mathrm{dL}$ or OGTT $\geq 200 \mathrm{mg} / \mathrm{dL}$ ) or A1c $\geq 6.5 \%$, according to the American Diabetes Association criteria 17. Diabetes category means diagnosis of diabetes, at the baseline of the study, without previous diagnosis.

Insulin resistance was assessed by homeostasis model assessment of insulin resistance (HOMAIR) by the $[\mathrm{FG}(\mathrm{mg} / \mathrm{dL}) \times 0.0555 \mathrm{X}$ plasma fasting insulin $(\mathrm{mUI} / \mathrm{L})] / 22.5$. Insulin resistance was defined by HOMA-IR $\geq 90 \%$ percentile (P90) of the variable distribution 18 .

Sex was categorized as male or female; the age was analyzed in years; the race /skin color was selfreported and categorized as black, brown, white, and others (including Asians and Indians); and the schooling was categorized in elementary, high school, and higher education. Diabetes in first-degree relatives was self-reported (family history of diabetes) 13 .

Prevalent coronary heart disease was defined by the report of myocardial infarction and/or myocardial revascularization 13 .

Anthropometry was performed by trained examiners using standardized techniques and equipment. BMI was calculated using weight $(\mathrm{kg})$ divided by square of height $\left(\mathrm{m}^{2}\right)$. Health-related behaviors were assessed by the participants' self-report. Physical activity in leisure time was evaluated by the International Physical Activity Questionnaire (IPAQ) in the modified long version and participants were classified into three groups: low, moderately, or very active, according to the sum of the weekly metabolic equivalents - a combination of type, frequency, and duration of the physical activities performed 13. Participants were classified as never smoked, ex-smokers, or smokers. Ex-smokers were those who smoked at least 100 cigarettes throughout a lifetime and current smokers, who still smoked at the time of the interview 13 .

The intake of dairy, animal protein, fructose, and alcoholic beverages were assessed by a validated semi quantitative Food Frequency Questionnaire (FFQ) 19,20,21. Frequency and the amount of dairy consumed were assessed, resulting in the evaluation of the intake categories in servings/day. Alcohol consumption was analyzed as grams/week and fructose as grams/24h 19 .

Arterial hypertension was defined by a self-reported medical diagnosis of hypertension, use of anti-hypertensive drugs, or blood pressure $\geq 140 \times 90 \mathrm{mmHg}$ at the moment of evaluation (sum of two measures, after five minutes of rest in the sitting position) 13 .

\section{Statistical analysis}

Continuous variables were described by means and standard deviation (SD) or median value and interquartile range (IQR; 25th to 75th percentile), according to the distribution of the data. Categorical variables were described by frequencies and proportions. ANOVA test was used to compare means, and Kruskal-Wallis for the medians across glycemic status categories.

The association of variable glycemic status with SUA levels (continuous) and other explanatory variables was investigated by univariate analysis. All the variables with $\mathrm{p}$-value $<0.20$ and those clinically relevant, regardless of whether $\mathrm{p}<0.20$ in the univariate analysis, were pre-selected to enter multinomial logistic regression models with "glycemic status" as the response variable, and SUA levels as the variable of interest. A low number of participants had chronic kidney disease $(\mathrm{n}=$ 521). Sensitivity analysis showed that the exclusion of them did not affect the results. Therefore, we are presenting analysis with adjustment by GFR rather than with the exclusion of these participants.

Models were consecutively adjusted as follows: Model 1 - glycemic status, SUA (continuous), age (continuous), sex, race/skin color, schooling, family history of diabetes; Model 2 - Model 1 plus BMI, systolic and diastolic blood pressure, prevalent coronary heart disease, and glomerular filtration rate; Model 3 - Model 2 plus physical activity, smoking, alcohol and dairy intake, fructose and animal protein consumption, triglycerides, and HDL cholesterol; Model 4 - Model 3 plus use of medicines that may interfere with uricemia (diuretics, losartan, fenofibrate, acetylsalicylic acid, gout medications). Tests were conducted on whether uric acid levels and fructose intake were effect modifiers on the associations of glycemic status by multiplicative interaction terms between uric acid/fructose 
intake. Additionally, tests were conducted on whether SUA and skin color were effect modifiers on the associations of glycemic status by multiplicative interaction terms between uric acid/skin color. We performed sensitivity analysis with categorical BMI, stratified into four categories according to nutritional status: underweight, eutrophic (reference), overweight and obesity.

The strength of the associations between the variables in the regression analysis was verified by odds ratio (OR) and confidence intervals (95\%CI).

Logistic regression models were used to test the association between SUA levels and insulin resistance (yes/no), as the response variable, with the same adjustments and including multiplicative interaction terms between uric acid/fructose intake.

Sex-specific analysis were performed, and for the female sex we also included estrogens therapy used for postmenopausal, in Model 4.

All analyses were performed using the statistical software Stata 14 (https://www.stata.com) with a $5 \%$ significance level and the p-values were two sided.

The study was approved by the Research Ethics Committees of the six participating centers and the Brazilian National Commission for Ethics in Research (CONEP/MS 976/2006).

\section{Results}

Data from 13,207 participants were analyzed. The mean (standard deviation) age was $51.4( \pm 8.9)$ years, with $55.2 \%$ of females. Most participants had university degree (54\%), and self-reported race/ skin color as white (53.2\%). A family history of diabetes was present in $37 \%$. The mean SUA was $5.5 \mathrm{mg} / \mathrm{dL}( \pm 1.5)$, with $6.4 \mathrm{mg} / \mathrm{dL}( \pm 1.4)$ for men and $4.8 \mathrm{mg} / \mathrm{dL}( \pm 1.2)$ for women. The prevalence of hyperuricemia in the total sample was $18.4 \%(\mathrm{n}=2,430), 25.1 \%$ among men and $13.0 \%$ among women.

The mean FG was $101.6 \mathrm{mg} / \mathrm{dL}( \pm 16.3)$ in total sample, $104.9 \mathrm{mg} / \mathrm{dL}( \pm 19.2)$ among males, and $98.8 \mathrm{mg} / \mathrm{dL}( \pm 12.8)$ among females. The median OGTT was $118.7 \mathrm{mg} / \mathrm{dL}$ (IQR: 101.3-140.8). The mean BMI was $26.7 \mathrm{~kg} / \mathrm{m}^{2}( \pm 4.6)$. There were 1,439 participants with newly diagnosed diabetes at the baseline cohort, and the prevalence of coronary disease was $2.5 \%$. The median HDL cholesterol was 55mg/dL (IQR: 47-65). Among these participants, 91\% consumed less than $175 \mathrm{~g}$ alcohol/week, and the median dairy consumption was 3.4 (IQR: 2.0-5.4) servings/day. The median fructose intake was 21.6g/day (IQR: 14.9-31.0). The mean GFR was $85.9 \mathrm{~mL} / \mathrm{min} / 1.73 \mathrm{~m}^{2}( \pm 14.9)$.

Insulin resistance was defined by HOMA-IR value of 4.18 , which corresponds to P90. Insulin resistance was evidenced in 1,327 participants, $10 \%$ of the final sample, most of them male.

In Table 1, data of the sample study is depicted according to the glycemic status. After all adjustments, higher SUA levels were significantly associated with impaired glycemic status. For each $1 \mathrm{mg} /$ $\mathrm{dL}$ increase in SUA levels, the odds of IFG, IGT and diabetes, was, respectively, 15\%, 23\% and $37 \%$ higher (Table 2). In the overall sample, we adjusted for the waist-to-hip ratio and there was no relevant change in OR (data not shown). Table 2 shows the sensitivity analysis, stratified by sex. The positive association between SUA levels and altered glycemic status remained significant after stratification. After sensitivity analysis with categorical BMI, the OR of IFG, IGT and diabetes was 1.17 (95\%CI: 1.08 ; 1.27$)$, 1.25 (95\%CI: 1.16 ; 1.35$)$ and 1.40 (95\%CI: 1.26 ; 1.54$)$, respectively, maintaining the positive association. The association between higher SUA levels and altered glycemic status was stronger among women. SUA levels were positive and significantly associated with insulin resistance in the general population $\mathrm{OR}=1,24$ (95\%CI: $1.13 ; 1.36)$ and after stratification by sex (Table 3). Higher SUA had a strong association with insulin resistance, mainly among women. 
Table 1

Characteristics of the study population according to glycemic status. ELSA-Brasil at baseline (2008 to 2010) $(N=13,207)$.

\begin{tabular}{|c|c|c|c|c|c|}
\hline Characteristics & $\begin{array}{l}\text { Normal glycemia } \\
\quad(n=4,936)\end{array}$ & $\begin{array}{c}\text { IFG } \\
(n=2,790)\end{array}$ & $\begin{array}{c}\text { IGT } \\
(n=4,042)\end{array}$ & $\begin{array}{l}\text { Diabetes mellitus } \\
\qquad(n=1,439)\end{array}$ & p-value \\
\hline \multicolumn{6}{|l|}{ Sociodemographic } \\
\hline Age [mean (SD)] & $48.9(8.4)$ & $52.0(8.6)$ & $52.8(9.1)$ & $55.1(8.3)$ & 0.062 \\
\hline Sex [n (\%)] & & & & & 0.083 \\
\hline Male & $1,738(35.2)$ & $1,588(56.9)$ & $1,806(44.7)$ & $789(54.8)$ & \\
\hline Female & $3,198(64.8)$ & $1,202(43.1)$ & $2,236(55.3)$ & $650(45.2)$ & \\
\hline Schooling [n (\%)] & & & & & $<0.001$ \\
\hline Elementary & $331(6.7)$ & $351(12.6)$ & $553(13.7)$ & 307 (21.3) & \\
\hline High school & $1,667(33.8)$ & 878 (31.5) & $1,435(35.5)$ & $558(38.8)$ & \\
\hline Higher education & $2,938(59.5)$ & $1,561(55.9)$ & $2,054(50.8)$ & $574(39.9)$ & \\
\hline Race/Skin color [n (\%)] & & & & & 0.001 \\
\hline Black & $656(13.4)$ & $328(11.9)$ & $706(17.7)$ & $318(22.4)$ & \\
\hline Brown & $1,355(27.7)$ & $771(28.0)$ & $1,126(28.2)$ & $421(29.6)$ & \\
\hline White & $2,743(56.1)$ & $1,551(56.4)$ & $2,026(50.7)$ & $624(43.9)$ & \\
\hline Others & $134(2.8)$ & $102(3.7)$ & $137(3.4)$ & $59(4.1)$ & \\
\hline Family history of diabetes mellitus [n (\%)] & $1,573(32.2)$ & $1,003(36.5)$ & $1,558(39.1)$ & $640(45.3)$ & 0.034 \\
\hline \multicolumn{6}{|l|}{ Health-related behaviors } \\
\hline Smoking status [n (\%)] & & & & & 0.418 \\
\hline Never & $3,143(63.7)$ & $1,535(55.0)$ & $2,239(55.4)$ & $695(48.3)$ & \\
\hline Ex-smoker & $1,198(24.3)$ & $892(32.0)$ & $1,219(30.2)$ & $522(36.3)$ & \\
\hline Smoker & $595(12.0)$ & $363(13.0)$ & $584(14.4)$ & $222(15.4)$ & \\
\hline Alcohol consumption (grams/week) [n (\%)] & & & & & 0.854 \\
\hline$<175$ & $4,660(94.4)$ & $2,440(87.5)$ & $3,694(91.4)$ & $1,224(85.1)$ & \\
\hline$\geq 175<350$ & $208(4.2)$ & $266(9.5)$ & $238(5.9)$ & $144(10.0)$ & \\
\hline$\geq 350$ & $68(1.4)$ & $84(3.0)$ & $110(2.7)$ & $71(4.9)$ & \\
\hline Physical activity [n (\%)] & & & & & 0.001 \\
\hline Intensive & $422(8.7)$ & $223(8.1)$ & $259(6.5)$ & $55(3.8)$ & \\
\hline Moderate & 769 (15.9) & $484(17.5)$ & $621(15.5)$ & 209 (14.7) & \\
\hline Low & 3,645 (75.4) & $2,052(74.4)$ & $3,113(78.0)$ & $1,163(81.5)$ & \\
\hline Dairy products [median (IQR P25-75)] & $3.5(2.1-5.5)$ & $3.3(1.9-5.3)$ & $3.3(1.9-5.3)$ & $3.1(1.7-5.1)$ & 0.0001 \\
\hline Animal protein consumption [median (IQR P25-75)] & $78(58-105)$ & $80(60-109)$ & $80(57-112)$ & $84(60-119)$ & 0.0001 \\
\hline Fructose intake [median (IQR P25-75)] & $21.1(14.7-29.8)$ & $21.2(14.8-31.1)$ & $22.3(15.1-31.8)$ & $23.1(15.7-34.3)$ & 0.0001 \\
\hline \multicolumn{6}{|l|}{ Laboratory tests and comorbidities } \\
\hline \multicolumn{6}{|l|}{ Uric acid (mg/dL) [mean (SD)] } \\
\hline Male & $6.1(1.3)$ & $6.4(1.3)$ & $6.6(1.4)$ & $6.8(1.5)$ & $<0.001$ \\
\hline Female & $4.4(1.0)$ & $4.9(1.1)$ & $5.0(1.2)$ & $5.5(1.2)$ & 0.385 \\
\hline GFR [mean (SD)] & $88.4(14.6)$ & $84.9(14.3)$ & $85.0(15.2)$ & $82.2(15.0)$ & 0.070 \\
\hline \multicolumn{6}{|l|}{$\mathrm{HDL}-\mathrm{C}(\mathrm{mg} / \mathrm{dL})$} \\
\hline Male & $51(44-58)$ & $49(43-57)$ & $48(43-56)$ & $48(42-55)$ & 1.000 \\
\hline Female & $62(54-73)$ & $60(51-71)$ & $59(50-69)$ & $56(49-65)$ & 1.000 \\
\hline Triglycerides (mg/dL) [median (IQR P25-75)] & $94(70-131)$ & $118(85-168)$ & $123(88-173)$ & $149(105-218)$ & $<0.001$ \\
\hline Hypertension [n (\%)] & 980 (19.9) & $898(32.2)$ & $1,527(37.8)$ & $811(56.4)$ & $<0.001$ \\
\hline BMI (kg/m²) [median (IQR P25-75)] & $24.8(22.6-27.4)$ & $26.3(24.0-29.1)$ & $26.9(24.2-30.1)$ & $28.6(25.6-31.9)$ & 0.001 \\
\hline Waist-to-hip ratio [mean (SD)] & $0.85(0.1)$ & $0.90(0.1)$ & $0.90(0.1)$ & $0.94(0.1)$ & 0.001 \\
\hline Coronary disease [n (\%)] & $68(1.5)$ & $64(2.5)$ & $121(3.2)$ & $54(4.0)$ & 0.627 \\
\hline
\end{tabular}

BMI: body mass index; GFR: glomerular filtration rate; HDL-C: high density lipoprotein cholesterol; IFG: impaired fasting glucose; IGT: impaired glucose tolerance; IQR: interquartile range; SD: standard deviation.

Note: statistical test ANOVA and Kruskal Wallis. 


\section{Table 2}

Association between glycemic status and uricemia in the general population and stratified by sex. ELSA-Brasil baseline $(N=13,207)$.

\begin{tabular}{|c|c|c|c|c|c|}
\hline & $\begin{array}{l}\text { Unadjusted model * } \\
\text { OR }(95 \% \mathrm{Cl})\end{array}$ & $\begin{array}{c}\text { Model } 1 \\
\text { OR }(95 \% \mathrm{Cl})\end{array}$ & $\begin{array}{c}\text { Model } 2 \\
\text { OR }(95 \% \mathrm{Cl})\end{array}$ & $\begin{array}{c}\text { Model } 3 \\
\text { OR }(95 \% \mathrm{Cl})\end{array}$ & $\begin{array}{c}\text { Model } 4 \\
\text { OR }(95 \% \mathrm{Cl})\end{array}$ \\
\hline \multicolumn{6}{|c|}{ Study population } \\
\hline \multicolumn{6}{|l|}{ IFG } \\
\hline Uric acid & $1.48(1.43 ; 1.53)$ ** & $1.34(1.28 ; 1.39)$ ** & $1.21(1.16 ; 1.27)$ ** & $1.14(1.09 ; 1.20)$ ** & $1.15(1.06 ; 1.25) * *$ \\
\hline \multicolumn{6}{|l|}{ IGT } \\
\hline Uric acid & $1.45(1.40 ; 1.49)$ ** & $1.46(1.40 ; 1.51) * \star$ & $1.31(1.26 ; 1.37)$ ** & $1.24(1.18 ; 1.29)$ ** & $1.23(1.14 ; 1.33)$ ** \\
\hline \multicolumn{6}{|l|}{ Diabetes } \\
\hline Uric acid & $1.80(1.72 ; 1.87) * *$ & $1.74(1.66 ; 1.83) * *$ & $1.48(1.40 ; 1.57) * *$ & $1.31(1.23 ; 1.39) * *$ & $1.37(1.24 ; 1.51) * *$ \\
\hline \multicolumn{6}{|l|}{ Male } \\
\hline \multicolumn{6}{|l|}{ IFG } \\
\hline Uric acid & 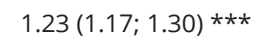 & $1.23(1.16 ; 1.29) * * \star$ & $1.12(1.05 ; 1.19) * \star \star$ & $1.07(1.00 ; 1.14) * \star \star$ & $1.15(1.02 ; 1.29) * \star *$ \\
\hline \multicolumn{6}{|l|}{ IGT } \\
\hline Uric acid & $1.33(1.27 ; 1.40) * \star \star$ & $1.33(1.26 ; 1.40) * \star \star$ & $1.19(1.12 ; 1.26) * \star \star$ & $1.13(1.06 ; 1.21) * \star \star$ & $1.15(1.02 ; 1.29) * \star \star$ \\
\hline \multicolumn{6}{|l|}{ Diabetes } \\
\hline Uric acid & $1.49(1.40 ; 1.59) * * *$ & $1.48(1.39 ; 1.58) * \star \star$ & $1.23(1.14 ; 1.32) * \star *$ & $1.10(1.01 ; 1.19) * \star *$ & $1.20(1.04 ; 1.39) * * *$ \\
\hline \multicolumn{6}{|l|}{ Female } \\
\hline \multicolumn{6}{|l|}{ IFG } \\
\hline Uric acid & $1.53(1.43 ; 1.63) * * *$ & $1.44(1.36 ; 1.54) * * *$ & $1.30(1.20 ; 1.40) * * *$ & $1.20(1.11 ; 1.30) * \star *$ & $\begin{array}{l}1.19(1.02 ; 1.38) * * * \\
1.19(1.02 ; 1.38) * * *, \#\end{array}$ \\
\hline \multicolumn{6}{|l|}{ IGT } \\
\hline Uric acid & $1.70(1.62 ; 1.80) * * *$ & $1.60(1.51 ; 1.69) * * *$ & $1.45(1.36 ; 1.55)$ *** & $1.35(1.26 ; 1.44) * \star *$ & $\begin{array}{l}1.29(1.14 ; 1.47) * * * \\
1.30(1.15 ; 1.48) * * *, \#\end{array}$ \\
\hline \multicolumn{6}{|l|}{ Diabetes } \\
\hline Uric acid & $2.43(2.26 ; 2.62) * \star *$ & $2.16(1.99 ; 2.33) * * *$ & $1.93(1.76 ; 2.12) * \star *$ & $1.66(1.51 ; 1.83) * \star *$ & $\begin{array}{l}1.70(1.41 ; 2.04) * * * \\
1.70(1.42 ; 2.05) * * *, \#\end{array}$ \\
\hline
\end{tabular}

95\%Cl: 95\% confidence interval; HDL-C: high density lipoprotein cholesterol; IFG: impaired fasting glucose; IGT: impaired glucose tolerance; OR: odds ratio.

* The associations are for a $1 \mathrm{mg} / \mathrm{dL}$ difference;

** $\mathrm{p}<0.001$

$* * * \mathrm{p}<0.05$

\# Adjusted for estrogens therapy used for postmenopausal women.

Note: Model 1 = adjustment by age, gender, family history of diabetes, education and race/skin color; Model $2=$ Model $1+$ body mass index, systolic and diastolic blood pressure, coronary artery disease and glomerular filtration rate; Model 3 = Model 2 + health-related behaviors, HDL-c e triglycerides, animal protein consumption and dairy products; Model 4 = Model $3+$ use of medicines. 


\section{Table 3}

Association between insulin resistance assessed by homeostasis model assessment of insulin resistance (HOMA-IR $\geq$ P90) and uricemia in the general population and stratified by sex. ELSA-Brasil baseline (2008-2010) $(\mathrm{N}=13,207)$.

\begin{tabular}{|c|c|c|c|c|c|}
\hline & $\begin{array}{l}\text { Unadjusted model * } \\
\text { OR }(95 \% \mathrm{Cl})\end{array}$ & $\begin{array}{c}\text { Model } 1 \\
\text { OR }(95 \% \mathrm{CI})\end{array}$ & $\begin{array}{c}\text { Model } 2 \\
\text { OR }(95 \% \mathrm{CI})\end{array}$ & $\begin{array}{c}\text { Model } 3 \\
\text { OR }(95 \% \mathrm{CI})\end{array}$ & $\begin{array}{c}\text { Model } 4 \\
\text { OR }(95 \% \mathrm{CI})\end{array}$ \\
\hline \multicolumn{6}{|c|}{ General population } \\
\hline Uric acid & $1.56(1.50 ; 1.61) * \star$ & $1.59(1.52 ; 1.66) * \star$ & $1.28(1.22 ; 1.36) * \star$ & $1.19(1.12 ; 1.26) * *$ & $1.24(1.13 ; 1.36) * \star$ \\
\hline \multicolumn{6}{|l|}{ Male } \\
\hline Uric acid & $1.45(1.37 ; 1.52) * * \star$ & $1.43(1.36 ; 1.51) * \star \star$ & $1.16(1.09 ; 1.24) * \star \star$ & $1.10(1.03 ; 1.18) * \star \star$ & $1.19(1.05 ; 1.35) * \star \star$ \\
\hline \multicolumn{6}{|l|}{ Female } \\
\hline Uric acid & $1.95(1.82 ; 2.09) * \star \star$ & 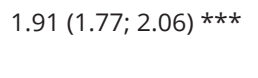 & $1.55(1.42 ; 1.69) * \star \star$ & 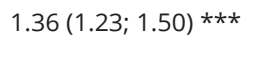 & $\begin{array}{l}1.34(1.12 ; 1.61) * * \star \\
1.36(1.13 ; 1.63) * \star *, \#\end{array}$ \\
\hline
\end{tabular}

95\%Cl: 95\% confidence interval; HDL-C: high density lipoprotein cholesterol; IFG: impaired fasting glucose; IGT: impaired glucose tolerance; OR: odds ratio.

* The associations are for a $1 \mathrm{mg} / \mathrm{dL}$ difference;

** $\mathrm{p}<0.001$;

*** $\mathrm{p}<0.05$

\# Adjusted for estrogens therapy used for postmenopausal women.

Note: Model 1 = adjustment by age, gender, family history of diabetes, education and race/skin color; Model 2 = Model $1+$ body mass index, systolic and diastolic blood pressure, coronary artery disease and glomerular filtration rate; Model $3=$ Model $2+$ health-related behaviors, HDL-c e triglycerides, animal protein consumption and dairy products; Model 4 = Model 3 + use of medicines.

\section{Discussion}

This study investigated the association between glycemic status and SUA levels in men and women at the baseline of a large cohort of Brazilian adults. After adjusting for demographic, anthropometric, health conditions, laboratory variables, and for the intake of some food groups, alcoholic beverages, and use of medicines, it was observed that higher SUA levels were independently associated with abnormal glycemic status and insulin resistance. These results were demonstrated in both genders, with higher association among female participants, and without influence of estrogenic drugs used for hormonal postmenopausal therapy.

Some authors have demonstrated an association between higher SUA levels and hyperglycemia. Prospective data from the original Framingham Heart Study, showed there was a high independent risk of future diabetes development in those with higher uricemia, in a positive linear progression; including in young adults, reaching a $20 \%$ higher risk for each $1 \mathrm{mg} / \mathrm{dL}$ increase in SUA 22.

Our findings were consistent with the literature. Kramer et al. 6 investigated the incidence of diabetes in individuals with normal glycemia, IFG, and IGT, with mean age of 63.3 years. The risk of diabetes increases by $60 \%$ for each $1 \mathrm{mg} / \mathrm{dL}$ higher baseline SUA, after several adjustments. The SUA cut-off of $5.35 \mathrm{mg} / \mathrm{dL}$ had a $100 \%$ negative predictive value for incident diabetes, after almost two decades of follow-up.

However, in contrast to this study, other researchers did not find an association between SUA and altered glycemic status. A study with American adults from the third National Health and Nutrition Examination Survey 10 found an inverse association between higher SUA levels and diabetes, but there is no mention about adjustments for drugs such as allopurinol. A Chinese cohort 9 with more than 4,400 participants also evaluated the association between SUA, xanthine oxidase activity, and diabetes development. There was an association between SUA and diabetes, but this association was lost after adjustment for xanthine oxidase activity. The authors concluded that elevated xanthine oxidase activity, but not SUA, has been associated with an increased risk of developing diabetes.

Another study 11 evaluated the association between SUA levels and diabetes among more than 24,000 participants of eight European countries. Although a positive association between the increase 
in SUA level and risk of diabetes was found, there was no causal relationship between the variables after analysis by Mendelian randomization, using a genetic score with 24 uric acid associated loci. Other studies have also shown an association between SUA and incident diabetes. Mendelian randomization, however, did not provide evidence for a causal link between them 23,24.

A meta-analysis emphasized that urate plays an important role in insulin resistance; and higher SUA was associated with an increased risk of developing diabetes 4. Hyperuricemia reduces the bioavailability of nitric oxide - fundamental for the cellular uptake of glucose - which could be a mechanism that would, partially, explain insulin resistance 3,25 . On the other hand, hyperinsulinemia leads to an increase in SUA due to a reduction in uric acid secretion; since insulin stimulates the expression of the urate transporter 1 (URAT1), which increases renal urate reabsorption, generating accumulation of plasma uric acid 3,25. The rapid hepatic synthesis of uric acid from fructose(a sugar commonly added to beverages, soft drinks, and processed foods) causes mitochondrial oxidative stress, via activation of NADPH oxidase, which stimulates insulin resistance and fat accumulation regardless of excessive caloric intake 12 . The likely mechanism in which fructose induces hyperuricemia is due to the increased degradation of adenosine triphosphate to adenosine monophosphate, a precursor of uric acid 12.

A review article evaluated uricemia as a marker of metabolic syndrome. It was observed that the association between hyperuricemia, cardiovascular disease, and elevation of proinflammatory cytokines implicated in the development of atherosclerosis 26 . Increased levels of markers and mediators of inflammation are related to changes in blood glucose and in insulin sensitivity. Uric acid may induce oxidative stress on adipocytes, by inflammatory cytokines synthesis via NADPH oxidase, generating insulin resistance 12. Interleukin-6 and tumor necrosis factor $\alpha$ (TNF- $\alpha$ ) appear to interfere with insulin, signaling pathways and beta cell function. TNF- $\alpha$ facilitates serine phosphorylation of the insulin receptor substrate 1, altering the phosphatidylinositol 3-kinase pathway and reducing insulin sensitivity 12,27 .

Inhibition of $\beta$-cell function by SUA may occur through several insulin signaling pathways, such as the adenosine monophosphate-activated protein kinase pathway. This is due to the overproduction of reactive oxygen species and oxidative damage, causing inhibition of proliferation and growth of $\beta$-cells. The kinase pathway is regulated by extracellular signaling and the nuclear transcription factor kappa B 28,29.

The pathogenesis of diabetes is complex and multifactorial, in which overweight, sedentary lifestyle, dietary habits, genetic factors, and age are highly relevant factors 1,17 . Despite all the knowledge about these factors, the prevalence of diabetes has increased in a worrisome way, with Brazil being the fifth country with the largest number of individuals with diabetes 1,2 .

The population of this study, according to the data presented, shows a high risk of insulin resistance and altered glycemic status development, since most participants were middle-aged, with the mean BMI of $26.7 \mathrm{~kg} / \mathrm{m}^{2}( \pm 4.6)$, and reported a sedentary behavior. We adjusted for BMI to avoid confusion bias due to the causal relationship between obesity and diabetes. Even after conducting a sensitivity analysis with categorical BMI, stratified into four categories according to nutritional status, the association between SUA and impaired glycemic status remained positive.

The most relevant positive aspects of our study are the rigor in the collection and processing of data and the large sample size, which allowed the analysis of men and women, separately. It has been shown that there are strong sex-specific effects in the genetic basis of urate production and excretion 8,30 . We adjusted it in females using hormonal postmenopausal therapy, as there is evidence that estrogen exerts an uricosuric effect, interfering with uricemia 31 . Other positives aspects are the fact that it is a multicenter study carried out in different Brazilian regions, with diverse genetic profile. We adjusted for important confounding factors, such as skin color, glomerular filtration rate, and use of interfering drugs. Another significant adjustment was dietary intake of dairy products and animal protein recognized as factors that can be protective or increase the risk of hyperuricemia and diabetes, respectively 12,32 . We also tested whether SUA and skin color were effect modifiers on glycemic status associations by multiplicative interaction terms between uric acid/skin color, with no change in OR. A positive, statistically significant, association persisted after we tested for effect modification by fructose intake, a sugar associated with the rapid uric acid hepatic synthesis, insulin resistance, and hyperglycemia 12 . 
Finally, this is a cross-sectional study and it is not possible to show a causal relation between explanatory variables and the outcomes assessed. No residual confounding factors were considered, such as the xanthine oxidase activity and genetic profile.

Our work is innovative because we approach the association of SUA and altered glycemic status in the Latin American population, in a large sample, with almost 14,000 participants. With an estimated population of $50 \%$ white and $43 \%$ black and brown, this study proves to be remarkably diverse from the studies that addressed the topic, essentially with a Caucasian or Asian population.

We also made adjustments and an interaction term for the fructose intake and the consumption of dairy products, which may be related to SUA levels and glycemia.

Despite being a cross-sectional analysis, this study is related to a large Latin American sample, and Brazil has the fifth largest diabetes population in the world 2, many still without diagnosis and treatment.

In sum, despite all current scientific knowledge of pathogenesis, diagnosis, and therapy, the high incidence of type 2 diabetes - and all the consequences of its diagnosis - remain a major focus on public health, with worldwide interest. In our study, we sought to clarify the association between SUA, a low cost, simple and accessible biomarker, and hyperglycemia, trying to better understand a residual factor that influences the development of diabetes. There was a positive, independent, and significant association between SUA levels and altered status of glycemia, diabetes, and insulin resistance, mainly in women.

SUA is an accessible and simple laboratorial test, and a potentially modifiable factor. Investigating the SUA levels, especially in patients diagnosed with pre-diabetes and insulin resistance, may be relevant for clinical and public health purposes. Further studies can be developed to answer challenging questions about this association in populations with diverse genetic background.

\section{Contributors}

A. I. R. Galvão wrote the manuscript, designed the study and the study's analytic strategy, analyzed the data, and conduct the literature review. A. M. R. Beleigoli designed the study and the study's analytic strategy, analyzed the data, and helped with the statistical analysis of the data. P. G. Vidigal and S. L. Appleton critically reviewed and edited the manuscript for important intellectual content. B. B. Duncan, M. I. Schmidt, and S. M. Barreto helped with the statistical analysis of the data and critically reviewed and edited the manuscript for important intellectual content. M. F. H. S. Diniz designed the study and the study's analytic strategy, analyzed the data, conduct the literature review, and critically reviewed and edited the manuscript for important intellectual content. All authors approved the final version of the manuscript.

\section{Additional informations}

ORCID: Aline Isabel Rodrigues Galvão (00000002-1405-3897); Alline Maria R. Beleigoli (00000002-7848-3183); Pedro Guatimosim Vidigal (0000-0001-8035-1350); Bruce Bartholow Duncan (0000-0002-7491-2630); Maria Inês Schmidt (0000-0002-3837-0731); Sarah L. Appleton (00000001-7292-9714); Sandhi Maria Barreto (00000001-7383-7811); Maria de Fátima Haueisen Sander Diniz (0000-0001-9146-5003).

\section{Acknowledgments}

We thank all participants in the ELSA-Brasil cohort, the entire team that acted synergistically, the Brazilian Ministry of Health and the Brazilian Ministry of Science and Technology. 


\section{References}

1. NCD Risk Factor Collaboration. Worldwide trends in diabetes since 1980: a pooled analysis of 751 population-based studies with 4.4 million participants. Lancet 2016; 387:1513-30.

2. International Diabetes Federation. IDF diabetes atlas. https://www.diabetesatlas.org/data/ en/ (accessed on 19/Jan/2020).

3. Maiuolo J, Oppedisano F, Gratteri S, Muscoli C, Mollace V. Regulation of uric acid metabolism and excretion. Int J Cardiol 2016; 213:8-14.

4. Kodama S, Saito K, Yachi Y, Asumi M, Sugawara A, Totsuka K, et al. Association between serum uric acid and development of type 2 diabetes. Diabetes Care 2009; 32:1737-42.

5. Jia Z, Zhang X, Kang S, Wu Y. Serum uric acid levels and incidence of impaired fasting glucose and type 2 diabetes mellitus: a meta-analysis of cohort studies. Diabetes Res Clin Pract 2013; 101:88-96.

6. Kramer CK, von Mühlen D, Jassal SK, BarrettConnor E. Serum uric acid levels improve prediction of incident type 2 diabetes in individuals with impaired fasting glucose: The Rancho Bernardo Study. Diabetes Care 2009; 32:1272-3.

7. Viazzi F, Leoncini G, Vercelli M, Deferrari G, Pontremoli R. Serum uric acid levels predict new-onset type 2 diabetes in hospitalized patients with primary hypertension: the MAGIC study. Diabetes Care 2011; 34:126-8.

8. van der Schaft N, Brahimaj A, Wen KX, Franco $\mathrm{OH}$, Dehghan A. The association between serum uric acid and the incidence of prediabetes and type 2 diabetes mellitus: The Rotterdam Study. PLoS One 2017; 12:e179482.

9. Li X, Meng X, Gao X, Pang X, Wang Y, Wu X, et al. Elevated serum xanthine oxidase activity is associated with the development of type 2 diabetes: a prospective cohort study. Diabetes Care 2018; 41:884-90.

10. Bandaru P, Shankar A. Association between serum uric acid levels and diabetes mellitus. Int J Endocrinol 2011; 2011:604715.

11. Sluijs I, Holmes MV, van der Schouw YT, Beulens JWJ, Asselbergs FW, Huerta JM, et al. A Mendelian randomization study of circulating uric acid and type 2 diabetes. Diabetes 2015; 64:3028-36.

12. Johnson RJ, Nakagawa T, Sanchez-Lozada LG, Shafiu M, Sundaram S, Le M, et al. Sugar, uric acid, and the etiology of diabetes and obesity. Diabetes 2013; 62:3307-15.

13. Schmidt MI, Duncan BB, Mill JG, Lotufo PA, Chor D, Barreto SM, et al. Cohort profile: Longitudinal Study of Adult Health (ELSABrasil). Int J Epidemiol 2015; 44:68-75.

14. Aquino EM, Barreto SM, Bensenor IM, Carvalho MS, Chor D, Duncan BB, et al. Brazilian Longitudinal Study of Adult Health (ELSABrasil): objectives and design. Am J Epidemiol 2012; 175:315-24.
15. Fedeli LG, Vidigal PG, Leite CM, Castilhos CD, Pimentel RA, Maniero VC, et al. Logistics of collection and transportation of biological samples and the organization of the central laboratory in the ELSA-Brasil. Rev Saúde Pública 2013; 47 Suppl 2:63-71.

16. Barreto SM, Ladeira RM, Duncan BB, Schmidt MI, Lopes AA, Bensenor IM, et al. Chronic kidney disease among adult participants of the ELSA-Brasil cohort: association with race and socioeconomic position. J Epidemiol Community Health 2016; 70:380-9.

17. American Diabetes Association. Classification and diagnoses of diabetes. Diabetes Care 2019; 42 Suppl 1:S13-28.

18. Geloneze B, Vasques AC, Stabe CF, Pareja JC, Rosado LE, Queiroz EC, et al. HOMA1-IR and HOMA2-IR indexes in identifying insulin resistance and metabolic syndrome: Brazilian Metabolic Syndrome Study (BRAMS). Arq Bras Endocrinol Metabol 2009; 53:281-7.

19. Molina MCB, Faria CP, Cardoso LO, Drehmer M, Velasquez-Melendez JG, Gomes AL, et al. Diet assessment in the Brazilian Longitudinal Study of Adult Health (ELSA-Brasil): development of a food frequency questionnaire. Rev Nutr 2013; 26:167-76.

20. Aune D, Norat T, Romundstad P, Vatten LJ. Dairy products and the risk of type 2 diabetes: a systematic review and dose-response metaanalysis of cohort studies. Am J Clin Nutr 2013; 98:1066-83.

21. Tian S, Xu Q, Jiang R, Han T, Sun C, Na L. Dietary protein consumption and the risk of type 2 diabetes: a systematic review and meta-analysis of cohort studies. Nutrients 2017; 9:982.

22. Bhole V, Choi JW, Kim SW, Vera M, Choi H. Serum uric acid levels and the risk of type 2 diabetes: a prospective study. Am J Med 2010; 123:957-61.

23. Keerman M, Yang F, Hu H, Wang J, Wang F, Li $Z$, et al. Mendelian randomization study of serum uric acid levels and diabetes risk: evidence from the Dongfeng-Tongji cohort. BMJ Open Diabetes Res Care 2020; 8:e000834.

24. Pfister R, Barnes D, Luben R, Forouhi NG, Bochud M, Khaw KT, et al. No evidence for a causal link between uric acid and type 2 diabetes: a Mendelian randomisation approach. Diabetologia 2011; 54:2561-9.

25. Toyoki D, Shibata S, Kuribayashi-Okuma E, Xu N, Ishizawa K, Hosoyamada M, et al. Insulin stimulates uric acid reabsorption via regulating urate transporter 1 and ATP-binding cassete subfamily G member 2 . Am J Physiol Renal Physiol 2017; 313:F826-34.

26. Billiet L, Doaty S, Katz JD, Velasquez MT. Review of hyperuricemia as new marker for metabolic syndrome. ISRN Rheumatol 2014; 2014:852954. 
27. Wang X, Bao W, Liu J, Ouyang YY, Wang D, Rong $\mathrm{S}$, et al. Inflammatory markers and risk of type 2 diabetes: a systematic review and meta-analysis. Diabetes Care 2013; 36:166-75.

28. Zhang Y, Yamamoto T, Hisatome I, Li Y, Cheng W, Sun N, et al. Uric acid induces oxidative stress and growth inhibition by activating adenosine monophosphate-activated protein $\mathrm{ki}$ nase and extracellular signal-regulated kinase signal pathways in pancreatic $\beta$ cells. Mol Cell Endocrinol 2013; 375:89-96.

29. Sun X, Zhang R, Jiang F, Tang S, Chen M, Peng D, et al. Common variants related to serum uric acid concentrations are associated with glucose metabolism and insulin secretion in a Chinese population. PLoS One 2015; 10:e0116714.
30. Döring A, Gieger C, Mehta D, Gohlke H, Prokisch H, Coassin S, et al. SLC2A9 influences uric acid concentrations with pronounced sexspecific effects. Nat Genet 2008; 40:430-36.

31. Yahyaoui R, Esteva I, Haro-Mora JJ, Almaraz MC, Morcillo S, Rojo-Martínez C, et al. Effect of long-term administration of cross-sex hormone therapy on serum and urinary uric acid in transsexual persons. J Clin Endocrinol Metab 2008; 93:2230-3.

32. Silva MTD, Diniz MFHS, Coelho CG, Vidigal PG, Telles RW, Barreto SM. Intake of selected foods and beverages and serum uric acid levels in adults: ELSA-Brasil (2008-2010). Public Health Nutr 2020; 23:506-14. 


\section{Resumo}

Há uma controvérsia na literatura a respeito da associação entre níveis de ácido úrico sérico (AUS) e glicemia. Portanto, avaliamos a associação entre AUS e glicemia (glicemia em jejum alterada, intolerância glicêmica e diabetes mellitus), além da resistência insulínica, em uma amostra grande no Brasil. O estudo transversal observacional incluiu 13.207 participantes com idade entre 35 e 74 anos na linha de base (2008-2010) do Estudo Longitudinal de Saúde do Adulto (ELSA-Brasil). Foi realizada análise de regressão multivariada para testar a associação entre AUS e glicemia (glicemia em jejum alterada, intolerância glicêmica e diagnóstico novo de diabetes tipo 2 na linha de base da coorte) depois de ajustar para idade, sexo, cor, indice de massa corporal, atividade física, tabagismo, consumo de álcool, comorbidades e uso de medicação. O modelo de regressão logística foi usado para avaliar a associação entre AUS e resistência insulinica por HOMA-IR. Foram realizadas análises estratificadas por sexo. A média de idade (DP) foi $51,4(8,9)$ anos, e 55,2\% dos participantes eram mulheres. Houve 1.439 novos diagnósticos de diabetes. Depois de todos os ajustes, o AUS esteve associado à glicemia em jejum alterada, intolerância glicêmica e diabetes, com odds ratio $(O R)=1,15$ (IC95\%: 1,06; 1,25), 1,23 (IC95\%: 1,14; 1,33) e 1,37 (IC95\%: 1,24; 1,51), respectivamente. Houve uma associação entre níveis de AUS e resistência insulínica, com OR = 1,24 (IC95\%: 1,13; 1,36). Na análise estratificada por sexo, persistiu a associação independente entre AUS elevado e glicemia. Os resultados sugerem que níveis elevados de AUS estão associados de maneira significativa com a glicemia em uma população latino-americana grande, sobretudo entre mulheres.

Diabetes Mellitus; Ácido Úrico; Intolerância à Glucose; Resistência à Insulina

\section{Resumen}

Hay un conflicto en la literatura respecto a la asociación entre los niveles de ácido úrico sérico (AUS) y el estado glucémico. Por eso, evaluamos la asociación entre el nivel AUS y el estatus glucémico: glucosa alterada en ayunas (GAA), tolerancia a la glucosa alterada (TGA) y diabetes mellitus (diabetes), comparados con la resistencia a la insulina en un amplio estudio en Brasil. Se realizó un estudio transversal, observacional con 13.207 participantes, con edades comprendidas entre los 35-74 años, en la base de referencia del Estudio Longitudinal de Salud entre Adultos brasileños (2008-2010) (ELSA-Brasil). Se realizó un análisis de regresión multinomial para probar la asociación entre AUS y el estado glucémico (GAA, TGA y de nuevo la diabetes tipo 2, diagnosticada en la cohorte como base de referencia) tras los ajustes por edad, sexo, color de piel, indice de masa corporal, actividad física, fumar, consumo de alcohol, comorbilidades, uso de medicinas. Se usó el modelo de regresión logística para evaluar la asociación entre AUS y la resistencia a la insulina por el HOMA-IR. Se realizó también un análisis estratificado por sexo. La media de edad (desviación estándar) fue 51,4 (8,9) años, un 55,2\% de los participantes eran mujeres. Hubo 1.439 nuevos casos de diabetes diagnosticados. Tras todos los ajustes, una AUS más alta estuvo asociada con GAA, TGA y diabetes, con odds ratio $(O R)=$ 1,15 (IC95\%: 1,06; 1,25), 1,23 (IC95\%: 1,14; 1,33), y 1,37 (IC95\%: 1,24; 1,51), respectivamente. Hubo asociación entre los niveles AUS y la resistencia a la insulina con $O R=1,24$ (IC95\%: 1,13; 1,36). En el análisis estratificado por sexo, una AUS más alta persistía independientemente asociada con un estado glucémico alterado. Nuestros resultados sugieren que unos niveles más altos de AUS estuvieron significativamente asociados con el estado glucémico en una amplia población latinoamericana, principalmente entre mujeres.

Diabetes Mellitus; Ácido Úrico; Intolerancia a la Glucosa; Resistencia a la Insulina
Submitted on 04/Sep/2020

Final version resubmitted on 14/Dec/2020

Approved on 22/Dec/2020 